\title{
Rechtspleging in Recht der Werkelijkheid
}

\author{
Popper is niet blij, maar het is feest ${ }^{*}$
}

\author{
Leny de Groot-van Leeuwen
}

\section{Een bescheiden oogmerk}

Recht der Werkelijkheid is voortgekomen uit de behoefte aan een wetenschappelijk forum voor het vakgebied van de sociaalwetenschappelijke bestudering van het recht. Daarbij werd gedacht aan de rechtssociologie, rechtsantropologie en rechtspsychologie, aldus de redactie in 1986 . $^{1}$ Een forumfunctie voor eigen kring, dat was het bescheiden oogmerk. Het tijdschrift zou een 'bundeling van de belangrijkste resultaten uit de drie genoemde disciplines' moeten bieden. ${ }^{2}$ In de loop van de tijd werd deze ambitie uitgebreid; meer deeldisciplines zouden moeten worden vertegenwoordigd en meer bijdragen gericht op een internationaal publiek zouden moeten worden opgenomen.

Zijn deze ambities waargemaakt op het gebied van rechtspleging? In Recht der Werkelijkheid van de afgelopen vier decennia, van 1980 tot 2020, verschenen meer dan dertig artikelen op dit aandachtsgebied, de boekbesprekingen en overige bijdragen niet meegerekend. Onderstaand worden enkele bijdragen over rechtspleging bezien in vogelvlucht. Het accent ligt op de forumfunctie van het tijdschrift, waarbij de belangrijke thema's die gedurende die tijd aan de orde zijn geweest worden aangestipt.

Deze lezer, voormalig redactielid, redactiesecretaris en redactieraadvoorzitter van Recht der Werkelijkheid en auteur van deze bijdrage, heeft door de jaren heen veel profijt gehad van de artikelen en zeker ook van de in het algemeen in wetenschappelijke kring ondergewaardeerde boekbesprekingen en inleidende bijdragen van de redactie.

\section{Recht en taal}

Van meet af aan treffen we in het tijdschrift artikelen en besprekingen aan over de relatie tussen recht en taal. Peter Bal bespreekt in 1988 de dissertatie van Bax over de conversie van rechtshandelingen, de omzetting door de rechter van een nietige rechtshandeling in een geldige rechtshandeling. Het juridisch discours wordt geanalyseerd waarbij Bax het constructieproces laat zien waarin 'levens'feiten worden omgezet in rechtsfeiten aan de hand van een proces-verbaal van een zitting. Deze teksttransformaties zijn, zijns inziens, niet specifiek voor deze

\footnotetext{
* De auteur wil graag Anita Böcker bedanken voor haar wijze opmerkingen bij een eerdere versie van deze bijdrage.

1 Redactioneel, 1986, p. 2.

2 Redactioneel, 1986, p. 3.
} 
rechtsfiguur; conversie is niet bijzonder, maar de gewone gang van zaken in rechtsvinding. Bax beperkt zich niet tot het wetenschappelijk publiek, maar richt zich ook tot rechters, zoals blijkt uit de aanbeveling dat zij meer oog dienen te hebben voor de in alledaagse taal gestelde verhalen en dat zij met minder vanzelfsprekendheid de betekenis van die verhalen slechts aan de hand van de juridische vertaling ervan dienen vast te stellen. ${ }^{3}$ Zijn tekstanalyse van het proces van rechtspraak laat zien dat veronderstellingen over de afbeeldingsrelatie van rechtsfeiten en werkelijkheid in de praktijk van de rechtsvinding niet opgaan. Bal schreef een genuanceerde en rijke recensie. Hij helpt daarmee ook de op het gebied van de taalanalyse niet geïnformeerde lezer op weg en ontsluit in zijn bespreking de nationale en internationale, filosofische en sociologische literatuur, waarbij hij onder meer verbanden legt met het werk van Bennet en Feldman (1981), Habermas (1981) en Alexy (1978).

Een kritische bespreking van de dissertatie en klassieker van Peter Bal, Dwangkommunikatie in de rechtszaal, verscheen in $1991 .{ }^{4}$ De bespreking biedt een helder overzicht van het boek. Hierin staat de verbale interactie tussen rechter en verdachte tijdens een politierechterzitting centraal, die bepaald wordt door de machtsongelijkheid. Het is de rechter die het verloop en de uitkomst van de zitting bepaalt. Bal analyseert de transcripten van elf politierechterzaken en beziet de gang van zaken in confrontatie met de ideale gesprekssituatie van Habermas' communicatietheorie.

En in hetzelfde tijdschriftnummer borduurt Martha Komter in haar artikel 'De Verdeling van kennis in de rechtszaal' op haar beurt voort op het gedachtegoed van Bal. Ook bij haar staat de macht van de rechter om de gebeurtenissen in de rechtszaal te sturen centraal. ${ }^{5}$ Zij gebruikte (31) transcripties van strafrechtszaken, hetzelfde materiaal dat de basis vormde voor haar proefschrift uit $1998 .^{6}$

Machtsongelijkheid en taaltransformaties zijn eveneens thema's in het artikel van Doornbos over het snelrecht in asielzaken uit 1999, waarbij zij gebruikmaakt van observatieonderzoek en panels bestaande uit rechters, advocaten en INDmedewerkers. Hier is de context echter niet de rechtszaal, maar gaat het om de besluitvorming in een aanmeldcentrum en de rol van de asielzoeker hierin.

Duidelijk wordt uit de genoemde bijdragen hoe zowel juridische feiten als dossiers en processen-verbaal worden geconstrueerd en hoe die informatie uiteindelijk leidt tot beslissingen. De theoretische inzichten worden veelal gebruikt om een specifieke, nog niet eerder empirisch onderzochte context te beschrijven. Aan al deze publicaties liggen gedegen onderzoek en zorgvuldige analyses ten grondslag, kenbaar door gedetailleerde beschrijvingen van observaties, teksten en gesprekken. Daarin spelen niet alleen (rechts)sociologische methoden en theorieën een rol, maar ook die van de psychologie, taalfilosofie en taaltheorie. Herhaaldelijk komen we dezelfde auteurs uit binnen- en buitenland als inspiratiebron tegen, die worden aangevuld met nieuwkomers uit de vakliteratuur. 


\section{De consumenten van het recht}

Door de jaren heen verschenen meerdere artikelen over het gebruik en de beleving van rechtspleging door de consumenten van het recht; op drie daarvan ga ik nader in. ${ }^{7}$

De bijdrage van Delanoeij, Van Loon en Wouters uit 1992 over het verloop van civiele geschillen, is een fraai voorbeeld van hoe voortgebouwd wordt op theorie en resultaten van andermans onderzoek, in dit geval van Galanter, Felstiner, Fitzgerald, Miller en Sarat alsook van Blankenburg en Verwoerd, die we overigens vele malen tegenkomen in recensies, artikelen of met eigen bijdragen in Recht der Werkelijkheid. ${ }^{8}$ Delanoeij c.s. bekijken onder welke voorwaarden het recht in Vlaanderen gemobiliseerd wordt en maken een vergelijking met de Verenigde Staten en Australië. In hun bijdrage besteden zij aandacht aan geschilbeslechtingsmogelijkheden naast overheidsrechtspraak; een thema dat nog altijd actueel is. Hiermee staan zij in een traditie die tot op vandaag voortduurt.

In 2000 doen Bruinsma en Schillemans verslag van hun onderzoek naar tien korte gedingen in hoger beroep om de relatie tussen de proceservaringen van partijen en hun vertrouwen in de rechtspraak te onderzoeken. Zij doen dat in het licht van de attributietheorie. Deze theorie richt zich niet op het begin van een rechtsgeschil, maar juist op de uitkomst van de procedure: een gunstig resultaat wordt veelal toegeschreven aan eigen inspanningen en als de zaak verloren is, dan ligt het aan de ander, in casu de andere partij of de rechter. Deze psychologische en sociologische theorie dient twee jaar later eveneens als zoeklicht in een artikel over de procesbeleving in het civiele recht door Minekus. ${ }^{9}$ Daarnaast passeren in dit artikel tal van theorieën en studies de revue, zoals empirisch onderzoek naar procedurele rechtvaardigheid, klantwaarderingsonderzoek en de cognitieve dissonantietheorie. En wederom zijn daarbij vele bekende publicaties en auteurs (Bruinsma, Crombag, Schuyt, Genn, Thibaut \& Walker, Conley \& O’Bar) uit ons forum aanwezig.

Verkruisen en Doornbos verhalen in 2014 op basis van dossieronderzoek, participerende observatie en interviews over de ervaringen van rechtzoekenden en rechters met de behandeling van zaken in het bestuursrecht. ${ }^{10} \mathrm{Zij}$ laten zien dat deze, nieuwe, behandeling mede is ingegeven door allerlei psychologische en sociologische inzichten en daarmee meer dan voorheen is gericht op procedurele rechtvaardigheid, waardoor, zo is de verwachting, partijen meer geneigd zullen zijn de verplichtingen die voortvloeien uit de procedure te accepteren en wellicht dus ook zullen naleven. ${ }^{11}$ In 'Voorbij procedurele rechtvaardigheid' (2017) maakt Doornbos melding van de kanttekeningen die in de literatuur bij de theorie van procedurele rechtvaardigheid zijn geplaatst. ${ }^{12} \mathrm{Zij}$ stelt vast dat de theorie van procedurele rechtvaardigheid in onderzoek en praktijk geliefd is en dat deze zeker zin

$7 \quad$ Zie o.a. diverse bijdragen in de specials van Recht der Werkelijkeid uit 2002 en 2017.

8 Delanoeije, Van Loon \& Wouters 1992.

9 Minekus 2002.

10 Verkruisen \& Doornbos 2014.

11 Eshuis 2010.

12 Doornbos 2017. 
heeft gehad. Zij heeft echter aarzelingen bij het steeds weer - in haar ogen al te enthousiast - beroep erop doen, waardoor het zicht op grote maatschappelijke problemen wordt ontnomen.

\section{De dienaren van het recht}

In 1989 worden maar liefst vier boeken, zeer kritisch, besproken over de Hoge Raad: twee dissertaties en twee bundels over deze opperdienaar van het recht. ${ }^{13}$ Boeken en auteurs - Van Koppen \& Ten Kate, Bruinsma, Blankenburg en Schuyt die alom de belangstelling hebben getrokken. Auteurs wier werk door de veertig jaar heen in Recht der Werkelijkheid besproken is en die ook op hun beurt artikelen en recensies daarin publiceerden, maar die ook langs andere paden met hun werk naar buiten traden en zo een breed publiek bereikten.

Het zijn niet alleen de leden van de Hoge Raad die in deze jaren onze belangstelling kregen. Publicaties verschenen over het Openbaar Ministerie, over de Duitse rechters gedurende de Tweede Wereldoorlog, over het privaatrechtelijk beslissingsgedrag van lagere rechters en over de executie van de gedurende een jaar gewezen eindvonnissen van de rechtbanken. ${ }^{14}$ En hierin zijn niet alleen sociologische en psychologische invloeden traceerbaar, maar ook economische en historische. In het veelbesproken themanummer Het Recht van de Geschiedenis bijvoorbeeld, ${ }^{15}$ waarin Roel Pieterman aan de hand van zijn proefschrift over de plaats van de rechter laat zien hoe een historische invalshoek het mogelijk maakt de theorievorming over het verband tussen macht en rationaliteit te verfijnen. ${ }^{16}$ Aldus wil hij, met behulp van aan Max Weber ontleende begrippen, een model bieden voor onderzoek.

In 2017, ten slotte, verschijnt het artikel 'De Civiele rechter als problem solver' van Van Rossum en Verschoof, dat een voorpublicatie is van hun boek Geschikt of niet geschikt? Schikkende rechters onder de loep. ${ }^{17}$ Naast de interventies van de rechters ter zitting en de effecten daarvan op de afloop van de zaak, stellen zij aan de orde of partijen deze interventies als procedureel rechtvaardig ervaren. Zij concluderen dat het gros van de rechtzoekenden in termen van procedurele rechtvaardigheid tevreden is over de zitting. Dat boek is op zijn beurt weer besproken door Eshuis. ${ }^{18}$ Doordat Eshuis expliciet kritiek uit en nauwgezet uiteenzet welke verbeterpunten er zijn, leren de lezers van deze bespreking veel over de vereisten voor het doen van goed onderzoek. Als eerste voorafgaand aan het onderzoek de hele opzet goed doordenken, de formulering van de onderzoeksvragen en de operatio-

\section{Griffiths 1989.}

Venema 2001, Van Koppen \& Ten Kate 1983, Ten Kate 1989.

Een themanummer waarover in NRC Handelsblad werd opgemerkt dat in de meeste artikelen er sprake is van puur historisch onderzoek waarbij gebruik wordt gemaakt van sociaalwetenschappelijke methoden (Mark Kuiper 16 april 1994). Zie ook de boekbesprekingen in Mens en Maatschappij door d'Anjou (1995) en in het Tijdschrift voor Sociologie van Meulders (1994).

Pieterman 1993.

Van Rossum \& Verschoof 2017.

Eshuis 2019. 
nalisering ervan, het ontwikkelen van de onderzoeksinstrumenten, de wijze waarop de data verwerkt zullen gaan worden enzovoort.

Hoewel Recht der Werkelijkheid geen tijdschrift voor methoden en technieken van de sociale wetenschappen is, leert de lezer gaande de jaargangen veel over onderzoek doen; dat gaat ook op voor alle hier besproken bijdragen over de drie thema's. Nieuwkomers en gevestigden in het vak kunnen hier hun voordeel mee doen.

\section{So what?}

De bevindingen van sociaalwetenschappelijk onderzoek van het recht hebben onmiskenbaar een plaats gevonden in de samenleving. Zo ook op het terrein van de rechtspleging. Is dit mede te danken aan Recht der Werkelijkheid? Vele bijdragen in het tijdschrift zijn een voorbode van latere publicaties in boek- of rapportvorm, worden in bewerkte vorm in een vaktijdschrift gepubliceerd of grijpen juist terug op eerdere publicaties. Daardoor alleen al is het moeilijk om de impact van een publicatie in het tijdschrift te bepalen; de onderzoeksresultaten kunnen immers net zo goed langs deze als langs andere, al dan niet oorspronkelijke, weg bij de buitenwereld terechtkomen. Het aantoonbaar gebruik door de samenleving van de bevindingen kan heel groot zijn, maar of het tijdschrift waarin daarvan gewag wordt gemaakt of andere bronnen daarin een doorslaggevende rol hebben gespeeld, blijft veelal onduidelijk. ${ }^{19}$ Het lijkt vrij waarschijnlijk dat een publicatie over hetzelfde empirische onderzoek in het Nederlands Juristenblad meer lezers trekt dan in Recht der Werkelijkheid.

Het veronderstelde bereik van het tijdschrift zorgde voor heftige discussies tussen vakgenoten die zich voor alles op de theorie en de ontwikkeling daarvan wierpen, en zich daarmee richtten op het wetenschappelijke forum, en degenen die zich primair richtten op beleidsonderzoek voor de rechtspraktijk. De laatsten waarschuwden voor navelstaren, hokjesgeest en zien 'een in zichzelf gekeerd wereldje dat zich heeft afgewend van de maatschappij'. ${ }^{20}$ 'De gerichtheid op theorie zou vrijwel niets relevants voor de praktijk te berde hebben gebracht doordat de auteurs zich terugtrekken op de eigen eilandjes van de wetenschappelijke rationaliteit.'

Maar was dit tijdelijk terugtrekken niet juist het primaire doel van het tijdschrift? Zou het niet een forum dienen te zijn voor de beoefenaren van de sociaalwetenschappelijke bestudering van het recht: 'ruimte bieden voor debat en uitwisselen van ideeën tussen vakgenoten'. ${ }^{21}$ Wellicht mag vooral van Recht der Werkelijkheid invloed op de eigen kring verwacht worden, opdat van daaruit de buitenwereld wordt bereikt.

19 Zie voor beoordelingscriteria wetenschappelijke kwaliteit en maatschappelijke relevantie van sociaalwetenschappelijk onderzoek, Naar een raamwerk voor de kwaliteitsbeoordeling van sociaalwetenschappelijk onderzoek, Amsterdam: KNAW 2013.

20 Huls 2001, p. 37.

21 De Groot-van Leeuwen \& Strijbosch 1997, p. 1. 
Bescheidenheid is uit de mode, maar ik denk dat de bescheiden ambities van Recht der Werkelijkheid niet zo slecht zijn uitgepakt: zij hebben geleid tot adequate uitwisseling van gedachten over onderzoeksaanpak en onderzoeksbevindingen tussen vakgenoten. Zoals uit de vorige paragrafen bleek, bood het tijdschrift plaats aan bijdragen uit de hele breedte van het onderzoeksveld van de sociaalwetenschappelijke bestudering van het recht, in het Nederlands of Engels, alwaar de vaak niet malse kritiek op elkaars werk tot uiting kon komen en die daardoor ook veilig kon worden ontvangen, zelfs door nieuwkomers in ons veld. Het Nederlands Juristenblad, Rechtsgeleerd Magazijn Themis, het Tijdschrift voor de Rechterlijke Macht en al die andere juridische vakbladen zijn daar mijns inziens minder geschikt voor. Door de auteurs wordt aantoonbaar gebruikgemaakt van elkaars onderzoekswerk.

\section{De ambitie waargemaakt}

Recht der Werkelijkheid heeft zijn sporen nagelaten binnen eigen kring en zo de empirische wetenschapsbeoefening, ook op het gebied van de rechtspleging, verrijkt. De forumfunctie is gerealiseerd: het tijdschrift biedt een forum voor gevestigden en nieuwkomers in het empirisch onderzoek. Dat heeft het ook mij geboden: het was de springplank die ik nodig had om, ook in onze internationale, sociaalwetenschappelijk-juridische kring, een plek te veroveren. Een betekenis die het niet alleen voor mij heeft gehad. Van het begin af aan zijn al Engelstalige artikelen opgenomen, waardoor ook langs directe weg de niet-Nederlandstalige wetenschappelijke wereld is bereikt, ${ }^{22}$ terwijl tevens een goed beeld is gepresenteerd van de belangrijkste thema's en bevindingen van het sociaalwetenschappelijk onderzoek naar het recht.

Bovendien laat het tijdschrift in de artikelen, boekbesprekingen en forumbijdragen zien dat het onderzoek in eigen kring serieus wordt genomen. Soms wordt in kritische beschouwingen een harde noot gekraakt over elkaars werk, ook dienen de bevindingen van de deelnemers aan het forum als inspiratiebron voor nieuw onderzoek, maar hypotheses worden er niet veel gefalsifieerd. Popper draait zich wellicht niet blij om in zijn graf, doch ik zie een feest van (h)erkenning.

\section{Referenties}

Anjou, L. d', Boekbespreking van Van den Bergh, G., C. Lorenz \& R. Pieterman (red.), Het recht van de geschiedenis; historische dimensies in sociaal-wetenschappelijk onderzoek van het recht, Special van Recht der Werkelijkheid, 1993-14(2), Mens en Maatschappij, 1995 (70), p. 89-91.

22 Sommige themanummers zijn geheel in het Engels verschenen, bijvoorbeeld: Von BendaBeckmann 1991, Bruinsma \& Nelken 2007, Arnoldussen e.a. 2016. Zelfs al in de voorganger van Recht der Werkelijkheid, de Nieuwsbrief voor Nederlandstalige Rechtssociologen, treffen we Engelstalige artikelen aan (Snyder 1983). Zie voor Engelstalige bijdragen omtrent rechtspleging, o.a. Van Koppen \& Ten Kate 1983 en Hofmann 2018. 
Arnoldussen, T., R. Knegt \& R. Schwitters (red.), 'Social Theoy and Legal Practices', Special van Recht der Werkelijkheid 2016-37(3).

Bal, P., 'Taal en recht', Recht der Werkelijkheid 1988-9(1), p. 113-120.

Benda-Beckmann, F. von (red.), Living Law in the Low Countries, Special van Recht der Werkelijkheid 1991-12(1).

Bergh, G. van den, 'Communicatie in het strafproces', Recht der Werkelijkheid 2001-22(1), p. $77-82$.

Bruinsma \& Nelken (red.), Explorations in Legal Cultures. Special van Recht der Werkelijkheid, 2007-28(3).

Delanoeije, E., F. van Loon \& Y. Wouters, 'Conflictbehandeling in Vlaanderen. Een empirisch onderzoek naar het verloop van burgerrechtelijk geschillen', Recht der Werkelijkheid, 1992-13(1), p. 79-97.

Doornbos, N., 'De toepassing van snelrecht in asielzaken: "werkelijkheid" en reconstructie', Recht der Werkelijkheid 1999-20(2), p. 1-22.

Doornbos, N., 'Voorbij procedurele rechtvaardigheid', Recht der Werkelijkheid 2017-38(2), p. 99-119.

Eshuis, R., 'Een verliezer is geen winnaar', Recht der Werkelijkheid 2010-31(2), p. 6-20.

Eshuis, R., 'Schikkende rechters onder de loep, Bespreking van R.J. Verschoof \& W. van Rossum, Geschikt of niet geschikt?', Recht der Werkelijkheid 2019-40(3), p. 65-68.

Griffiths, J., 'Het interessante van de Hoge Raad', Recht der Werkelijkheid 1989-10(1), p. 81-99.

Groot-van Leeuwen, L. de \& F. Strijbosch, 'Van de redactie', Recht der Werkelijkheid 1997-18(1), p. 1.

Hofmann, A., 'A bottom-up approach to litigation before the European Court of Justice', Recht der Werkelijkheid 2018-39(3), p. 70-74.

Hoven, P. van den, 'Bent u gelukkig?, Bespreking van P. Bal, Dwangkommunikatie in de rechtszaal. Een onderzoek naar de verbale interaktie tussen rechter en verdachte tijdens de strafzitting van de politierechter', Recht der Werkelijkheid 1991-12(2), p. 73-78.

Huls, N., Zonder recht geen rechtssociologie, Recht der Werkelijkheid 2001-16(2), p. 35-41.

Kate, J. ten, 'Schikkingen tijdens civielrechtelijke geschillen; enige psychologische kanttekeningen bij het gedrag van onderhandelaars', Recht der Werkelijkheid 1989-10(1), p. 63-80.

Komter, M., 'De verdeling van kennis in de rechtszaal', Recht der Werkelijkheid 1991-12(2), p. 3-19.

Koppen, P.J. van \& J. ten Kate, 'Use of information by the private law judge: An attributional model of judicial decision making', Recht der Werkelijkheid 1983-4(2), p. 262-282.

Malsch, M. (red.), 'De burger in de rechtspraak, ervaringen van niet-professionele procesdeelnemers', Special van Recht der Werkelijkheid, 2002-23(3).

Kuiper, M., 'Socio-historie' NRC Handelsblad, Boeken, p. 3, 16 april 1994.

Meulders, C., Boekbespreking van Van den Bergh, G., C. Lorenz \& R. Pieterman (red.), Het recht van de geschiedenis; historische dimensies in sociaal-wetenschappelijk onderzoek van het recht, Special van Recht der Werkelijkheid, 1993-14(2), Tijdschrift voor sociologie, 1994-15(2), p. 93-94.

Minekus, W., 'Over verliezers en zonebokken: procesbeleving en attributietheorie in het civiele recht', in: M. Malsch (red.), De burger in de rechtspraak, ervaringen en percepties van niet-professionele procesdeelnemers, Special van Recht der Werkelijkheid, 2002-23(3), p. $13-40$.

Pieterman, R., 'De plaats van de rechter macht en rationaliteit', in: G. van den Bergh, C. Lorenz \& R. Pieterman (red.), Het Recht van de Geschiedenis, Historische dimensies in 
sociaal-wetenschappelijk onderzoek van het recht, Special van Recht der Werkelijkheid, 1993-14(2), p. 29-50.

Rossum, W. van \& R. Verschoof, 'De civiele rechter als problem solver', in: H. Grootelaar, P. Mascini \& W. van Rossum (red.), Recht als probleemoplossing, Special van Recht der Werkelijkheid, 2017-38(2), p. 51-75.

Snyder, F., 'Three Paradigms in the Anthropology of Law', de Nieuwsbrief voor Nederlandstalige Rechtssociologen (NNR) 1983-4(1), p. 2-16.

Venema, D., 'Duitse rechters in Nederland 1940-1945', Recht der Werkelijkheid 2001-22(2), p. 87-90. 